\title{
Corrections of the type specimens of Liasis olivaceus barroni Smith, 1981 (Serpentes: Pythonidae)
}

\author{
Ryan J. Ellis \\ Department of Terrestrial Zoology, Western Australian Museum, 49 Kew St, Welshpool, 6106, Australia. \\ Email: ryan.ellis@museum.wa.gov.au
}

KEYWORDS - Nomenclature, ICZN, holotype, paratype, olive pythons, Pilbara, Gascoyne.

\section{INTRODUCTION}

In the description of Liasis olivaceus barroni Smith, 1981, the author incorrectly listed the registration numbers for the holotype and one paratype specimen. These errors inadvertently designated two other species, Ctenophorus caudicinctus macropus (holotype) and Underwoodisaurus milii (paratype) as type specimens, technically resulting in the placement of $L$. o. barroni into synonymy with $C$. caudicinctus macropus. Here the correct holotype and paratype specimens for $L$. olivaceus barroni are identified and the erroneous registration numbers and associated specimen data corrected.

Liasis olivaceus barroni or the Pilbara olive pythons are large uniformly coloured pythons endemic to the Pilbara and northern parts of the Gascoyne bioregions in Western Australia (Bush \& Maryan 2011). The subspecies was described in 1981 by Laurie A. Smith, in a revision of the Liasis olivaceus species-group in Western Australia. The description of L. o. barroni was based on eight specimens of the subspecies in addition to comparative material of other species examined by Smith. In the description Smith designated type specimens for the new subspecies in accordance with the International Code of Zoological Nomenclature (ICZN), then third edition (1964).The information provided for the holotype specimens was 'R55384, a juvenile collected at Tambrey, Western Australia, in $21^{\circ} 35^{\prime} \mathrm{S}$, $117^{\circ} 34^{\prime} \mathrm{E}$ by W.H. Butler on 7 July 1964'. Paratypes listed included 'Bamboo Creek (33420); Woodstock (54378); Marandoo (60708); 16 km from Nanutarra (24920); Paraburdoo (58935); Pipe Springs, 16 km W of Newman (54617); Prairie Downs (17694)'. All type specimens are held in the collection of the Western Australian Museum (WAM).

Following a review of the original description and associated specimens for a type specimen audit of the collection of the Western Australian Museum, two inconsistencies were identified between the registration numbers of the type series listed in the description, Smith's unpublished morphological and meristic data and the specimens associated with those numbers held in the WAM collection. The registration number listed by Smith for the Liasis olivaceus barroni holotype, R55384, refers to a specimen of the agamid lizard Ctenophorus caudicinctus macropus Storr, 1967 from $62 \mathrm{~km}$ east of Mount Isa, Queensland (2049'S, $\left.140^{\circ} 00^{\prime}\right)$ and one paratype specimen, R54617, a specimen of the carphodactylid gecko Underwoodisaurus milii (Bory de Saint-Vincent, 1823) from Steep Point, Western Australia $\left(26^{\circ} 09^{\prime} \mathrm{S}, 113^{\circ} 10^{\prime} \mathrm{E}\right)$.

Examination of specimens held in the type collection at the WAM, Smith's unpublished data, historical specimen registers and accession data revealed the correct holotype and paratypes examined for the original description and identified the derivation of the two errors. Smith's original specimen data collected during examination of specimens for the description presents morphological and meristic data for a total of ten specimens, one of which is crossed out (R2760, Cue, WA), later identified as a specimen of L. olivaceus olivaceus (Smith 1981a). Of the remaining nine specimens, one entry is annotated with 'Type', although paratype specimens are not identified. Smith (1981a) stated eight specimens of L. olivaceus barroni were examined; however, Smith's unpublished data indicate nine specimens of the subspecies were examined, of which all but the holotype were destined to become paratypes (L.A. Smith, pers. comm.).

Examination of Smith's unpublished specimen data collected for the species description states 'R55383' with the locality 'Pindrunna, Tambrey' with a notation of 'Type' next to the specimen's registration number and locality. The registration number of the $L$. $O$. 
barroni specimen contained in the type collection with holotype labels is R55383. The location and collection information associated with this specimen matches those and the morphology of the specimen, and is comparable to that provided in the description. The erroneous holotype registration $\mathrm{R} 55384$ compared to the correct holotype registration R55383 vary only by a single digit (4 versus 3 ). Thus, it is clear which specimen was the desired holotype for the subspecies based on the matching type localities and minor numerical error. It is likely the error was a minor typographical error that occurred during the preparation of the manuscript on Smith's part.

In regards to the erroneous paratype specimen registration number, there are inconsistencies with the number of specimens examined presented in the description to Smith's unpublished data of morphology and meristic data of specimens examined. The data for the erroneous paratype presented in the description is associated with two remaining specimens examined by Smith. The specimen associated with the registration R45617 is a L. olivaceus barroni from Rhodes Ridge,

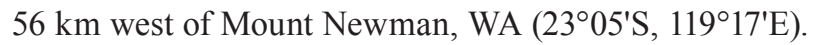
Despite the locality not matching the erroneous registration number presented in the description (R54617), the error of a reversal of the first two digits of the registration number (45 versus 54 ) can be easily identified. The specimen is also listed in error in Smith's unpublished data of examined specimens as R54617, locality '35 mi. W of Mt Newman' where is it likely to have been accidently carried on through to the description. This specimen is currently held in the type collection and labelled with a paratype tag. The locality for the erroneous paratype presented by Smith of 'Pipe Spring, $16 \mathrm{~km} \mathrm{~W}$ of Newman' is only associated with one other L. o. barroni specimen which is not listed as a type, R31143 from Pipe Spring, 10 miles $(16 \mathrm{~km})$ west of Mount Newman, WA $\left(23^{\circ} 20^{\prime} \mathrm{S}, 119^{\circ} 33^{\prime} \mathrm{E}\right)$. This specimen is correctly listed in Smith's list of examined specimens; however, it is not presented as a paratype in the description.

Following examination of the type specimens and Smith's unpublished data from specimens examined for the description it is apparent that the two specimens, R45617 and R31143 were both examined for the description of L. olivaceus barroni and should both have been listed as paratypes. It is not clear where the error originated in regards to the paratype. It appears, however, that the typographical error of the registration number of R45617 has resulted in the erroneous paratype listing of only one specimen with data from both. All specimens examined by Smith, excluding the holotype were to be designated as paratypes and all should have been listed as such (L.A. Smith, pers. comm.).

Other L. o. barroni specimens have been held in the collection historically which are not listed as material examined by Smith: R548, Marble Bar; R868, Pilbara Goldfield; R2248, Tambrey District and R8101, Tambrey (all from WA). Of these specimens, only one can be located within the WAM collection: R8101, a juvenile in poor condition. Of the remaining three specimens, one was disposed (R2248) and two others could not be located (R548 and R868) and are presumed lost or disposed. Until about 1950, it was common practice at the WAM to discard large sized specimens, particularly pythons that could be easily identified and not confused with other species once they had been identified and catalogued (Smith 1981b).

The correct registration numbers and associated localities for L. o. barroni type specimens are presented below with collector and date of collection as presented on accession forms. All specimens held in the WAM collection.

Holotype: R55383, Pindrunna, $32 \mathrm{~km}$ north-west of Tambrey, WA $\left(21^{\circ} 38^{\prime} \mathrm{S}, 117^{\circ} 36^{\prime} \mathrm{E}\right)$, W.H. Butler, 7 July 1964.

Paratypes: R17694, Prairie Downs, $8 \mathrm{~km}$ south of

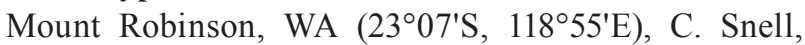
November 1962; R24920, Ashburton River, 16 km upstream from Nanutarra, WA $\left(22^{\circ} 37^{\prime} S, 115^{\circ} 37^{\prime} E\right)$, C.R. Barrett-Lennard, 1 May 1965; R31143, Pipe Springs, 10 mi [16 km] W Mt Newman, WA (2320'S, 119³3'E), C. Snell, December 1967; R33420, Bamboo Creek, WA $\left(20^{\circ} 54^{\prime} \mathrm{S}, 120^{\circ} 12^{\prime} \mathrm{E}\right)$ collected by A.M. Douglas, January 1969; R45617, Rhodes Ridge, $56 \mathrm{~km}$ west of Mount Newman, WA $\left(23^{\circ} 05^{\prime} \mathrm{S}, 119^{\circ} 17^{\prime} \mathrm{E}\right)$, collected by mining personnel, January 1974; R54378, Woodstock Station, WA (213' S, $\left.118^{\circ} 57^{\prime} \mathrm{E}\right)$, W.H. Butler, 6 May 1965; R58935, Paraburdoo, WA ( $\left.23^{\circ} 12^{\prime} \mathrm{S}, 117^{\circ} 40^{\prime} \mathrm{E}\right)$, collected by first aid officer, 1977; R60708, Marandoo $\left(22^{\circ} 38^{\prime} \mathrm{S}\right.$, $\left.118^{\circ} 07^{\prime} \mathrm{E}\right)$, J.S. Burt, 1 September 1978.

The corrections for the erroneous registration numbers were identifiable by review of information provided in the description and associated accession data in addition to Smith's unpublished data and notes. Further examination of specimens held in the collection of the WAM including those with identifiable holotype and paratype tags attached allowed confirmation of correct type specimens. These errors have not been identified earlier and have subsequently been incorrectly listed in the National Zoological Catalogue for Amphibia and Reptilia by Cogger et al. (1983). In the most recently published catalogue of snake species, Wallach et al. (2014) listed L. o. barroni as a synonym of Liasis olivaceus and did not provide any additional type specimen information for the $L$. o. barroni subspecies. Correction of the erroneous holotype and paratype registration numbers maintains nomenclatural stability without the need to nominate a neotype specimen as the error and correct holotype were easily identified. This minor error with considerable implications identifies the need for collection audits to take place, particularly for historic type specimens which are most likely to be missing or in error to maintain taxonomic and nomenclatural stability. 


\section{ACKNOWLEDGEMENTS}

I thank Paul Doughty (Western Australian Museum), Aaron Bauer (Villanova University) and Glenn Shea (University of Sydney and Australian Museum) for technical discussions in regards to the type specimens and nomenclature of Liasis olivaceus barroni and providing comments on earlier drafts of the manuscript. I especially thank Laurie Smith for technical discussions and assisting in the location of his original specimen notes and data used for the description which greatly assisted in resolving the errors and two reviewers for feedback on an earlier draft of this manuscript.

\section{REFERENCES}

Bory de Saint-Vincent, J. B. G. M. (1823). Phyllure de Milius, Phyllurus milii. (pp 183-184). In: Audouin, Bourdon, I., Brrongniart, A., de Candolle, d'Audebard de Ferussac, Deshayes, Desmoulins, Drapiez, Dumas, Edwards, Fee, A., Flourens, Saint-Hilaire, G., Saint-Hilaire, I. G., Guillemin, A., de Jussieu, A., Kunth, De La Fosse, G., Lamouroux, Latreille, Prevost, C., Richard, A. and Bory de Saint-Vincent (eds) Dictionnaire classique d'Histoire naturelle. Rey et Gravier: Paris, France.
Bush, B. and Maryan, B. (2011). Field Guide to Snakes of the Pilbara. Western Australian Museum: Perth, Australia.

Cogger, H. G., Cameron, E. E. and Cogger, H. M. (1983). Zoological Catalogue of Australia. Vol. 1. Amphibia and Reptilia. Australian Government Publishing Service: Canberra, Australia.

International Commission on Zoological Nomenclature [ICZN]. (1964). International Code of Zoological Nomenclature. Second Edition. The International Trust for Zoological Nomenclature: London, England.

Smith, L. A. (1981a). A revision of the Liasis olivaceus species-group (Serpentes: Boidae) in Western Australia. Records of the Western Australian Museum, 9: 227-233.

Smith, L. A. (1981b). A revision of the python genera Aspidites and Python (Serpentes: Boidae) in Western Australia. Records of the Western Australian Museum, 9: 211-226.

Storr, G. M. (1967). Geographic races of the agamid lizard Amphibolurus caudicinctus. Journal of the Royal Society of Western Australia, 50: 49-56.

Wallach, V., Williams, K. L. \& Boundy, J. (2014). Snakes of the World: A Catalogue of Living and Extinct Species. CRC Press: Boca Raton, U.S.A.

MANUSCRIPT RECEIVED 14 APRIL 2015; ACCEPTED 28 APRIL 2015. 